\author{
Л. Димитрова-Тодорова \\ Институт болгарского языка БАН \\ (Болгария, София) \\ lilidimtod@yahoo.com
}

\title{
Рец.: ХРИСТИНА ДЕЙКОВА. \\ ЭТИМОЛОГИЯ И ЛИНГВИСТИЧЕСКАЯ КОНТАКТОЛОГИЯ (РУМЫНСКИЕ ГЛАГОЛЬНЫЕ ЗАИМСТВОВАНИЯ В ОДНОМ БОЛГАРСКОМ ГОВОРЕ). Saarbrücken: LAP LAMBERT Academic Publishing, 2016, 208 c.
}

\begin{abstract}
Рецензия посвящена новой книге Х. Дейковой об одной интересной группе исключительно трудных для этимологизации глаголов в болгарском говоре, контак-

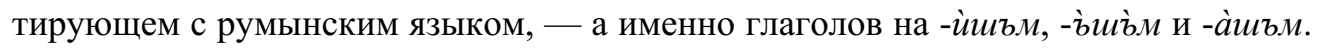
Подробно освещается содержание книги, подчеркивается новаторский комплексный подход исследовательницы, использование ею данных лингвистической контактологии, позволивших ей сделать вывод о том, что в данном говоре существует единая модель морфологической адаптации глагольных заимствований из румынского языка при помощи суффикса -шъ- (диалектного варианта общеболгарского суффикса -ca- из греческой аористной основы).

Ключевые слова: этимология, лингвистическая контактология, диалектология, заимствования.
\end{abstract}

В труде Хр. Дейковой обсуждаются проблемы болгарской этимологии, связанные с этимологизацией балканских заимствований в болгарском языке и в болгарских диалектах. Объектом анализа является один очень интересный тип глаголов

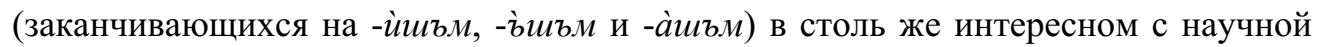
точки зрения говоре с. Ново село, Видинской области, который подробно изучен проф. Максимом Младеновым. В этом говоре наблюдаются процессы заимствования слов из румынского в болгарский язык; эти языки на протяжении многих веков находились в непрерывном контакте на общеязыковом и диалектном уровнях, в результате чего были созданы условия болгарско-румынской языковой интерференции.

Исследование состоит из Введения (с. 3-27), I главы (с. 28-125) и II главы (c. 126-166), Заключения (с. 165-175) и четырёх справочных разделов: Источники 
(c. 176-177), Литература (с. 178-189), Алфавитный указатель анализируемых слов (c. 190-193) и Сокращения (с. 194-195).

Во Введении (состоящем из трёх частей) представлены проблемы болгарской этимологии, связанные, с одной стороны, с так называемой диалектной этимологией (термин «обычно применяется к двум типам этимологических исследований, связанных, с одной стороны - с этимологизацией собственно диалектной лексики, а с другой стороны - с привлечением диалектной лексики при этимологизации литературных слов, праязыковых форм или слов родственных языков», с. 5) вслед за цитируемой Ж.Ж. Варбот, а с другой стороны, с так называемой контактной этимологией, которая «направлена на выяснение происхождения лексических единиц и языковых структур, перенесённых из одного языка в другой (или в другие) в ситуации языкового контактирования», с. 6. Совсем недавно (2013 г.) Р. Мейлхамер (R. Mailhammer) определил контактную этимологию как этимологическую субдисциплину со своими методологическими процедурами анализа на основе современных теорий языковых контактов С. Томасона (S. Thomason), T. Кауфмана (T. Kaufman) и Ф. ван Кутсема (F. van Coetsema). Следует подчеркнуть, что Хр. Дейкова сосредоточивает внимание на двух научных аспектах, которые очень актуальны для болгарской этимологии и для «Болгарского этимологического словаря». В этом словаре разрабатываются разнообразные случаи как диалектной этимологии (при объяснении диалектных слов со всей болгарской языковой территории), так и контактной этимологии (при объяснении многочисленных заимствований из соседних балканских языков в общенародный язык и диалекты). Здесь исследовательница несколько подробнее останавливается на методологических критериях в контактной этимологии (контактном сценарии / contact scenario, контактирующем языке / contact language и контактной структуре / contact structure) и, учитывая объект своего исследования (диалектную лексику, заимствованную в условиях языкового контакта между диалектами двух контактных языков), акцентирует внимание на трудностях, связанных с прояснением первого и третьего критериев (с. 9-12).

Хр. Дейкова выражает намерение рассматривать данные глаголы комплексно и системно, пытаясь дать им единое этимологическое объяснение. Её цель - показать возможности системного подхода для успешной этимологизации диалектной лексики при учёте системных закономерностей в рамках конкретного диалекта (в данном случае диалектные слова сгруппированы по структурному признаку). Одной из целей исследования является выяснение видовой характеристики рассматриваемых глаголов (в рамках заочной дискуссии с М. Сл. Младеновым) путём прояснения частного случая болгарско-румынской грамматической интерференции, который мог бы послужить доказательством в пользу выдвинутой этимологической гипотезы (в отношении общей концовки данных глаголов). Таким образом, на конкретном материале Хр. Дейкова стремится показать возможности полезного взаимодействия этимологии с лингвистической контактологией. Здесь хотелось бы особо подчеркнуть, что глаголы, являющиеся объектом данного исследования, исключительно трудны для этимологизации по отдельности, и что системный 
подход, который выбирает исследовательница, до сих пор не применялся в болгарской этимологии при этимологизации диалектной лексики.

Далее в исследовании представлен говор с. Ново село Видинской области с точки зрения ситуации болгарско-румынских языковых контактов; а также излагаются существующие отрывочные социолингвистические сведения, о данном говоре Ст. Младенова, который изучал говор в конце XIX в., а также М. Сл. Младенова, который подробно исследовал говор в 60-е гг. ХХ в.

В последней части Введения Хр. Дейкова представляет румынские глагольные заимствования и связанные с ними слова - объект её исследования (почерпнутые в основном из труда М. Сл. Младенова и частично из одной недавно вышедшей книги с диалектными текстами из с. Ново село Видинской области). Это такие глаголы, как: булдушйшъм, гушйшъм, дърнуйшъм, съ доспѝшъ, изворйшъ, клочѝшъм, съ к'орѝшъм, съ кънунйшъм, копилйшъм, лъпсь̀шъм, съ нъмолѝшъ, мошѝшъм, поликрйшъм, припонѝшъм, пръпъдйшъм, съ руменйшъм, съ ребецйшъм, съ скоколѝшъм, съ скороджѝшъ, съ стъфидѝшъ, судомйшъм, турта̀шъм и туртѝшъм, cъ фъсулйшъм, чугулйшъм и др. В сферу исследования также включены такие прилагательные, как гънфа̀шън, къпийа̀шън, фермека̀шън, фъръма̀шън, ъпука̀шън, по своему происхождению являющиеся страдательными причастиями от незасвидетельствованных в говоре глаголов, относительно которых можно предполагать заимствование из румынского языка.

Первая глава исследования посвящена этимологическому анализу глаголов,

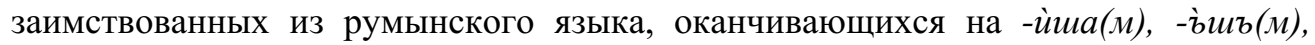
-а̀mъ(м). Отправной точкой при анализе служит этимологическая практика «Болгарского этимологического словаря» (БЭС), в котором объясняется 18 глаголов рассматриваемой группы - збъндйша се (= збъндйшъ съ), клочѝша се (= клочѝшъ съ), копилѝшам (= копилѝшъм), в статье ко̀пеле, кьорѝшам се (= к'орѝшъм съ), в статье кьор, льпсі̀шъм, мингуйшам, намолѝша (са) [= ні̀молѝшь (cъ)], в статье нъмо̀л, повестѝшъм, поликрйшъм, в статье полиेкра, припонйшам (= припонйшъм), пълишу̀въ съ, пълѝшъ съ и др. Хр. Дейкова справедливо считает неудовлетворительными и неполными толкования части перечисленных слов, она критически осмысливает данные толкования и приводит конкретные аргументы. Исследовательница подчёркивает отсутствие единства в объяснениях образования подобных глаголов и характера их концовок в «Болгарском этимологическом словаре». Одной из причин этого, по ее мнению, является изолированное объяснение части этих глаголов, не соотнесенных с другими подобными заимствованиями в данном говоре, вследствие чего автор исследования выбирает именно системный подход при этимологизации заимствованных глаголов, чтобы «преодолеть индивидуальность слова» (по Варбот).

Далее Хр. Дейкова объясняет происхождение форм -ѝma(м), -ѝmъ(м), -а̀mъ(м), которым или не уделяется никакого внимания в «Болгарском этимологическом словаре», или делается неубедительная, по мнению исследовательницы, попытка их объяснения. В процессе углубления их анализа Дейкова приводит диалектные данные и параллельные языковые процессы в качестве доказательных аргументов 
в пользу предложенного ею объяснения - сравнивает рассмотренные глаголы с другими румынскими глаголами-заимствованиями из болгарских говоров на территории Румынии (изученные также М. Сл. Младеновым и Ст. Стойковым), а также с глагольными заимствованиями из турецкого и греческого в болгарский язык. Таким образом она обнаруживает, что в данном говоре существует единая модель морфологической адаптации глагольных заимствований из румынского языка при помощи суффикса -шъ-, который является диалектным вариантом общеболгарского суффикса -ca- из греческой аористной основы. Исходя из морфологических особенностей предполагаемых румынских контактных диалектов, Дейкова

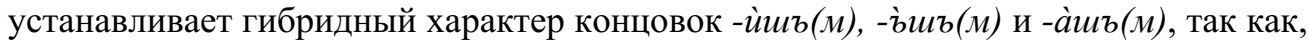
по её мнению, варианты вокальных расширений формантов обычно соответствуют аористной основе исходных румынских глаголов (автор поясняет, что имеет в виду глагольную основу прошедшего времени в форме аориста/простого перфекта в румынском языке, с. 63, сноска 50). Уместно сопоставить данные форманты с гибридными формантами -тис-/-дис-, при помощи которых адаптируются турецкие глагольные заимствования в болгарском языке. Способ заимствования греческих и турецких глаголов в их аористной форме давно установлен и применяется в практической работе над «Болгарским этимологическим словарем». Открытие, сделанное Хр. Дейковой, состоит в том, что таким образом могут объясняться также румынские глагольные заимствования в диалектах с сильным языковым взаимодействием - этот факт не был известен до сих пор. Таким образом, в конце исследовательница обобщает, что „проникновение глагольных заимствований в болгарский язык при непосредственном языковом контакте очень часто происходит путём перенесения аористных основ исходных глаголов, адаптированных, в свою очередь, с помощью формантов, являющихся по происхождению аффиксами с соотносимой грамматической семантикой (в конкретном случае речь идет о суффиксе -са от греческой аористной основы)“ (с. 169-170). Этот вывод имеет как теоретическое значение для балканского языкознания и лингвистической контактологии, так и бесспорное практическое значение для болгарской этимологии.

Далее в этой главе Хр. Дейкова приступает к конкретному этимологическому

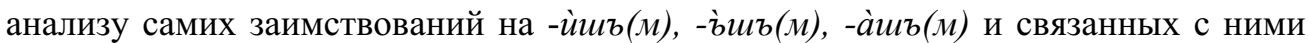
слов (всего 60 единиц). В результате внимательного и глубокого анализа Дейкова приходит к убедительным этимологиям, чему способствует и применяемый ею системных подход. В своём исследовании она впервые этимологизирует ряд глаголов новосельского говора или корректирует известные до сего дня попытки этимологизации, которые оказались неудачными именно из-за того, что рассматривались бессистемно. В этом исследовании очень ярко очерчиваются большие трудности, которые вызывает этимологизация балканских заимствований в болгарских диалектах, проникавших из одного языка в другой при посредничестве третьего (в этом конкретном случае заимствованные из румынского глаголы, образованные в румынском от греческих и турецких заимствований, которые, в свою очередь, заимствованы в болгарский, где имеются подобные производные; ср., например, зогръфѝшъм, с. 79-81, а также пересмотренные этимологии для съ к'орішым, 
с. 87-88, лъпсы̀шъм, с. 88, съ стъфидѝшъ, с. 105-106). В отношении болгаро-румынских языковых контактов не всегда легко установить также и обратные заимствования в болгарский (ср., например, пересмотренные автором этимологии съ нъмолѝшъ, с. 89-90, припонѝшъм, с. 92, съ пълишу̀ва, съ пълѝшъ, с. 93-94, както и съ руменѝшъм, с. 97-98, и др.). Неправдоподобность некоторых прежних этимологических объяснений, так же, как и отдельных гипотез, предложенных различными авторами, вызвана тем, что в процессе заимствования слов или в процессе языковой интерференции в исходных формах произошёл ряд изменений, чаще фонетических и морфологических. Хр. Дейкова более глубоко и аргументированно раскрывает наступившие изменения в форме и значении слов, а также случаи морфологической и семантической интерференции. При этимологическом анализе учитываются как фонетические и морфологические закономерности болгарского и румынского языка (в их историческом развитии), в данном случае их диалектов, так и семантика лексических основ и словообразовательных механизмов. Из-за описанных сложных процессов развития автор иногда предлагает более одного толкования. При этимологизации глаголов Хр. Дейкова (с. 116-120) выделяет такие, которые формально совпадают с основной группой, но образованы на болгарской диалектной почве от румынских или иных имён (существительных и прилагательных) по модели глагольных заимствований (ошишторѝшъм, съ слоенйшъ, съ фъсулйшъ).

Во второй главе исследования, посвящённой болгарско-румынской интерфе-

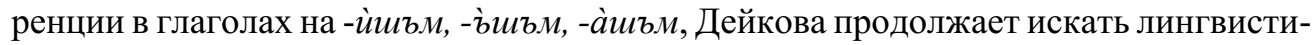
ческие и экстралингвистические аргументы в пользу своей основной этимологической гипотезы происхождения этих глаголов. Необходимость дальнейшего анализа связана с тем, что объяснение происхождения общей концовки данных глаголов, к которому она приходит в результате традиционного комплексного этимологического анализа, не объясняет, почему эти глаголы используются как двувидовые. По мнению Дейковой, М. Сл. Младенов необоснованно считает их imperfectiva tantum, а в соответствии с предложенным ею объяснением, т. е. формально, они должны были бы относиться к совершенному виду (в болгарских говорах Румынии подобные заимствования относятся к совершенному виду, при этом от них образуется вторичный несовершенный вид с суффиксом -ва-). Здесь автор исходит из основной специфики славянской категории вида, одновременно обращаясь к классическим и новым теориям языковых контактов. Основание для привлечения аргументов лингвистической контактологии она находит в так называемой контактной этимологии, для которой необходимо использовать результаты ареальных исследований, чтобы аргументировать предложенную этимологическую гипотезу иноязычного происхождения данного слова. После точного морфологического анализа глаголов, использованных в различных контекстах (в типичных глагольных временах или в условиях видовой конкуренции), автор подтверждает своё первоначальное утверждение о том, что данные глаголы двувидовые. Она приходит к выводу, что благодаря этой своей особенности они представляют частный случай грамматической интерференции, при которой речь идет о влиянии румынского 
языка (как языка-модели) на болгарский язык (как копирующий язык) (по Вайнрайху). Опираясь на две новые теории лингвистической контактологии (Томасона-Кауфмана и Ван Кутсема), Дейкова выясняет лингвистические причины этой интерференции, которые кроются в типологических различиях между двумя языками (в румынском языке нет категории вида глагола) и в особенности в славянской категории глагольного вида (Дейкова поддерживает позицию С. Иванчева, что это лексико-грамматическая категория), которая универсально маркирована, т. е. специфична и трудна для освоения иностранцами. Далее Хр. Дейкова переходит к последней части своего исследования, где новаторским образом применяет одну из методологических процедур в контактной этимологии, предложенную Мейлхаммером (т. наз. принцип калькирования/Blueprint Principle), пытаясь восстановить конкретную социолингвистическую (контактную) ситуацию, в которой возникли и развивались изучаемые глаголы и которая является плодом определённых географических, исторических, социальных и этнокультурных обстоятельств. Её цель - определить тип языкового контакта, который мог бы ответить на вопрос о двувидовом использовании глаголов (в результате интерференции). Дейкова представляет обе цитируемые выше теории, но в конце концов останавливается на теории Ван Кутсема, которую считает более приемлемой, потому что в ней учитывается динамичность языковой ситуации, наблюдаемая в Ново село. Так автор приходит к выводу, что заимствование румынских глаголов и их адаптация в качестве двувидовых в болгарском говоре осуществляется посредством двух основных типов языкового взаимодействия при контакте - borrowing (заимствование) и imposition (перенос/наложение), при этом в данных процессах участвуют как двуязычные болгары, так и двуязычные румыны, которые здесь, несомненно, были на более раннем историческом этапе, хотя М. Сл. Младенов и отмечает отсутствие массового билингвизма в данном селе в 60-е годы ХХ в. Другой вывод, к которому приходит автор, состоит в том, что утверждение в исследуемом диалекте данной специфической особенности (двувидовости глаголов румынского происхождения) является результатом «внутриязыковой склонности болгарского языка «терпеть» двувидовость» (с. 166). На основе данных заключений Хр. Дейкова присоединяется к приверженцам позиции множественности причин языковых изменений (т. е. одновременного действия внутренних и внешних причин) в развернувшейся в языкознании дискуссии по данному вопросу.

В Заключении точно и последовательно представляются в обобщённом виде результаты всего исследования, а приложенный алфавитный указатель и список сокращений в значительной степени облегчают использование исследования, в различных частях которого произведен всесторонний анализ языковых материалов.

Труд Христины Дейковой в целом плодотворен как в теоретическом, так и в практическом отношении. В нем применяется системный подход при этимологизации диалектной лексики, при этом соблюдается основной принцип комплексного анализа при установлении происхождения слов, автор исследования основывается на новых разработках в области контактной этимологии и теории языковых контактов и приходит к выводам, исключительно ценным не только для 
болгарской этимологии, но и для балканского языкознания и лингвистической контактологии в целом. Я считаю, что автор исследования очень убедительно разработала и применила на конкретном языковом материале теоретические принципы так называемой контактной этимологии. Таким образом она на практике показала, как достижения в других языковедческих областях (в том числе и в более новых языковедческих направлениях) могут быть использованы в этимологии. Новые методологические подходы, предложенные в книге, могут послужить основой для дальнейших этимологических исследований. Обобщения относительно способа заимствования и адаптации заимствованных румынских глаголов могут быть использованы также в теоретических разработках в области балканского языкознания и лингвистической контактологии. В практическом отношении предложенные ею этимологии будут очень полезны для дальнейшей работы над «Болгарским этимологическим словарём».

Этимологические исследования в настоящем труде представляют собой также вклад в прояснение очень важных для болгарской истории проблем, связанных с этногенезом части населения в конкретном болгарском регионе и в целом с миграционными процессами в Болгарии.

\author{
L. Dimitrova-Todorova \\ Institute of Bulgarian Language BAN \\ (Bulgaria, Sofia) \\ lilidimtod@yahoo.com
}

\title{
Review of: KHRISTINA DEIKOVA. ETYMOLOGY AND LINGUISTIC CONTACTOLOGY (ROMANIAN VERBAL BORROWING IN ONE BULGARIAN DIALECT). Saarbrücken: LAP LAMBERT Academic Publishing, 2016, 208 p.
}

The review is devoted to a new book by Kh. Deikova about an interesting group of verbs that are extremely difficult to etymologize in the Bulgarian dialect, which is in con-

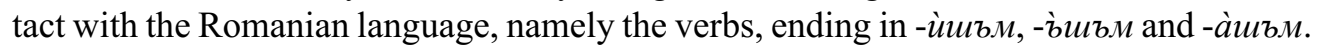
The contents of the book are highlighted in detail, the innovative complex approach of the researcher is emphasized, and the use of linguistic contactology data, which enabled her to conclude that in this dialect there is a single model of morphological adaptation of verbal borrowings from the Romanian language with the help of the suffix - wr- (dialect variant of the Bulgarian - $c a$ - from the Greek aorist base).

Key words: etymology, linguistic contactology, dialectology, borrowings.

Перевела с болгарского языка М. Н. Белова. 